\title{
Commission 41: History of Astronomy
}

\author{
PRESIDENT: Alexander A. Gurshtein \\ VICE-PRESIDENT: Nha Il-Seong \\ SECRETARY: Clive Ruggles \\ ORGANIZING COMMITTEE: David DeVorkin, Wolfgang Dick, \\ Radesh Kochhar, Tsuko Nakamura, Luisa Pigatto, \\ Richard Stephenson, and Brian Warner
}

\section{Introduction}

Following the Sydney General Assembly, the membership of C41 stood at 352, of whom, at the time of writing, three are known to have deceased. Since the formation of the Inter-Union Commission for the History of Astronomy (ICHA) prior to the Sydney General Assembly, C41/ICHA has subsequently acted, in effect, as an integrated Commission with a single OC. In this triennium the C41/ICHA OC made strong efforts to clarify and simplify the controversial issue of admitting non-IAU members to the ICHA. After prolonged and active consultation, the OC approved the document "Procedures for Admitting non-IAU members to the ICHA" and the OC Secretary Prof. Clive Ruggles officially presented this document to the history of astronomy community in C41/ICHA Newsletter no. 6. It is subject to ratification by the C41/ICHA Business Meeting in Prague in 2006.

\section{Principal Conferences and Publications}

One very welcome outcome of the new status of C41 within the IAU was that a historically focused conference received the status of IAU Colloquium 196. This meeting, "Transits of Venus: New Views of the Solar System and Galaxy", took place successfully at the University of Central Lancashire in the UK on 2004 June 7-11, to coincide with the 2004 transit of Venus. The Proceedings (554 pp.) were published in a timely manner by Cambridge University Press in 2005 June under the editorship of D. W. Kurtz (Lancaster University) Kurtz 2005. This Colloquium and Proceedings are undoubtedly among the highlights of the history of astronomy within the triennium in question.

Another key publication sponsored by the C41/ICHA was the Proceedings of the International Conference "Astronomical Instruments and Archives from the Asia-Pacific Region" held in the Republic of Korea in July 2002. These Proceedings (204 pp., large format) were published by Yonsei University Press (Korea) under the editorship of Wayne Orchiston, F. Richard Stephenson, Suzanne Debarbat and Nha Il-Seong in June 2004.

On 2005 July 25, during the 22nd International Congress on the History of Science in Beijing sponsored by the International Union on History and Philosophy of Science, the C41/ICHA arranged a Symposium entitled "Sharing the Celestial Sphere." The principal organizer of the Symposium was Rajesh Kochhar with support by Alex Gurshtein. The Symposium focused primarily on the early stages of human civilization. It demonstrated that studying the place of astronomy in ancient cultures where there is an absence of any 
written tradition brings numerous challenges, but nonetheless requires rigour. The session was well attended and warmly received, with lectures being followed by lively discussions. There was never any intention to produce a Proceedings volume, and contributions to the Symposium will be published as separate papers.

Also on the theme of ancient astronomy, C41/ICHA is collaborating in the organization of an international conference on archaeoastronomy to be held in April 2006 on the island of Rhodes, Greece. The principal organizer is Prof. Ioannis Liritzis (University of the Aegean) and at the time of writing the call for papers has been distributed.

\section{Astronomical Heritage}

In 2005, an undertaking that had been given by C41 more than a decade earlier was carried through to completion. The 1994 General Assembly in The Hague had passed a resolution concerning the preservation of the sites involved in measuring the Struve arc of the meridian through Dorpat, desiring their designation as World Heritage Sites. Under the watchful eye of Dr Alan Batten all the necessary procedures were successfully completed. The Struve arc has been officially recognized as an outstanding part of World Cultural Heritage.

On astronomy and world heritage in general, the Commission as a group and several individual fellows of C41 have participated actively since 2003 in the development of the new thematic initiative "Astronomy and the World Heritage" within UNESCO. The initiative was preliminarily approved by UNESCO's World Heritage Committee in July 2005, opening the way for relationship to astronomy to become one of the criteria under which UN member states may nominate cultural properties for inclusion in the World Heritage List.

The Sydney General Assembly unanimously approved the resolution initiated by the C41 to commemorate the four hundredth anniversary of the first telescopic observations by Galileo and to declare 2009 as the World Year of Astronomy. In accordance with this resolution, the IAU Executive Committee has established a special Working Group under the guidance of the IAU Immediate Past President, Dr Franco Pacini. The C41 President became a part of this Working Group, and anticipates many C41 members participating in this extraordinary event. The C41 President has also conveyed a proposal to the European Postal Authorities asking them to mark 2009 with a common stamp on astronomy issued by the members of the All-European Postal Administration.

\section{Working Groups}

During the triennium in question, C41 maintained four active Working Groups, namely Archives (chaired by Brenda G. Corbin), Astronomical Chronology (Alexander A. Gurshtein), Historical Instruments (Nha Il-Seong), and Transits of Venus (Steven J. Dick). A further Working Group, Historic Radio Astronomy (Wayne Orchiston), established under the aegis of C41, was promoted to Inter-Divisional level, between Divisions $\mathrm{X}$ and XII.

The Committee members of the Archives Working Group are: Dr Ileana Chinicci (Italy), Ms Brenda Corbin (USA, Chair), Dr Suzanne Dbarbat (France), Dr Wolfgang Dick (Germany), Mr Daniel Green (USA), Dr Wayne Orchiston (Australia), and Mr Adam Perkins (UK).

The Committee members of the Astronomical Chronology Working Group are: Dr Christine Allen (Mexico), Prof Adriaan Blaauw (Netherlands), Prof Alexander Gurshtein (Russia/USA, Chair), Dr Teije de Jong (Netherlands), and Prof Rajesh Kochhar (India). 
The Committee members of the Historical Instruments Working Group are: Dr Juergen Hamel (Germany), Mr Kevin Johnson (UK), Dr Tsuko Nakamura (Japan), Prof Nha IlSeong (Korea, Chair), Dr Wayne Orchiston (Australia), and Dr Sara Schechner (USA).

The Committee members of the Transits of Venus Working Group are: Dr Steven J. Dick (USA, Chair), Dr Hilmar Duerbeck (Germany), Dr Robert van Gent (Netherlands), Prof David Hughes (UK), Mr Willie Koorts (South Africa), Dr Wayne Orchiston (Australia), and Dr Luisa Pigatto (Italy).

Regular reports from all of these Working Groups are included in the C41/ICHA Newsletters. In addition, the activities of the Transits of Venus are summarized below. A report from the Historical Radio Astronomy Working Group is also included in the Commission 40/Division X Triennial Report.

\subsection{Transits of Venus}

Since the last General Assembly the Transit of Venus Working Group has published Progress Reports \#3 and \#4 in the Journal of Astronomical History and Heritage, volume 7 (June, 2004), pp. 50-52, and volume 8 (June, 2005), pp. 70-71. Reports\#1 and \#2 were published in the same journal, vol. 5 (December, 2002), pp. 185-188 and vol. 6 (June, 2003), p. 64. Readers are referred to these publications for details of the activities of the Working Group.

The most important event since the last General Assembly was the occurrence of the transit itself on June 8, 2004. Gordon Bromage and D. W. Kurtz organized IAU Colloquium 196 centered around this event. The meeting's venue, the University of Central Lancashire, Preston, UK, was near the site where Jeremiah Horrocks first observed a transit of Venus in 1639. To the delight of all present, on the day of the rare event almost the entire transit was observed from the tiny Lancashire village of Much Hoole, where Horrocks lived, and several other locations. Members of Commission 41 who presented historical papers included Allan Chapman, Suzanne Dbarbat, Wayne Orchiston, Luisa Pigatto, Steven Dick, Brian Warner and Mary T. Brck. There was also an excellent set of scientific papers. As already mentioned, the Proceedings were published as Kurtz 2005.

Historical markers continue to be erected to commemorate sites where transit of Venus observations were made. In addition to those listed in WG Report \#3, among the latest are two markers in San Antonio, Texas, one at Bullis House Inn commemorating the Belgian transit expedition, and another at Fort Sam Houston commemorating the American transit of Venus expedition, both in 1882 .

The Transit of Venus Working Group is organizing reports on the transit of Venus observations at the Prague General Assembly in 2006.

\section{Further Information}

C41 activities have been regularly publicized in the C41/ICHA Newsletters (Editorin-Chief: Dr Ileana Chinnici). These are now issued in electronic form on the Commission's web pages maintained by Dr Wolfgang Dick see w.astro.uni-bonn.de/pbrosche/ iaucomm41/news/). As a result, the Newsletters are now available not only to C41/ICHA members but also to every member of the IAU.

\section{References}

Kurtz, D.W. 2005, D.W. Kurtz (ed.), Transits of Venus (C196): New Views of the Solar System and Galaxy (Cambridge: Cambridge University Press).

Orchiston, W. 2005, Wayne Orchiston, F. Richard Stephenson, Suzanne Debarbat and Nha IlSeong (eds.), Astronomical Instruments and Archives from the Asia-Pacific Regions (Seoul: Yonsei University Press). 